\title{
Produção de Proteína Microbiana e Parâmetros Ruminais em Vacas Leiteiras Alimentadas com Farelo de Trigo 1
}

\author{
Carla Aparecida Soares ${ }^{2}$, José Maurício de Souza Campos $^{3}$, Rilene Ferreira Diniz Valadares ${ }^{4}$, \\ Sebastião de Campos Valadares Filho ${ }^{3}$, Sandro de Souza Mendonça ${ }^{5}$, Augusto César de Queiroz ${ }^{3}$, \\ Rogério de Paula Lana ${ }^{3}$, Robson Magno Liberal Véras ${ }^{6}$, Edilson Paes Saraiva $^{7}$
}

\begin{abstract}
RESUMO - Doze vacas Holandesas foram distribuídas em três quadrados latinos 4 x 4, balanceados de acordo com o período de lactação, com o objetivo de estimar a produção de proteína microbiana, utilizando-se a excreção total de derivados de purinas (DP) a partir de coletas spot de urina, as concentrações de nitrogênio (N)-uréia no plasma, no leite e na urina, o pH e a concentração de amônia ruminal. As quatro rações experimentais foram formuladas para conter na base da matéria seca $70 \%$ de silagem de milho e $30 \%$ de concentrado. Foram utilizados níveis crescentes de farelo de trigo no concentrado (0,33, 67 e 100\%) em substituição ao fubá de milho. As concentrações de uréia $(38,8 \mathrm{mg} / \mathrm{dL})$ e $\mathrm{N}$-uréia $(18,1 \mathrm{mg} / \mathrm{dL})$ no leite não foram afetados pelos níveis de farelo de trigo, assim como as concentrações plasmáticas de uréia $(51,1 \mathrm{mg} / \mathrm{dL})$ e $\mathrm{N}$-uréia $(23,8 \mathrm{mg} / \mathrm{dL})$. As excreções urinárias de uréia, $\mathrm{N}$-uréia, alantoína, DP, purinas absorvidas, $\mathrm{N}$-microbiano e concentração de alantoína no leite não foram alteradas. Entretanto, a excreção de ácido úrico apresentou comportamento quadrático, com valor máximo de 40,03 mmol/dia no nível de $36 \%$ de farelo de trigo. O pH e a concentração de amônia ruminal antes e após a alimentação também não foram afetados pelos níveis de farelo de trigo. O fubá de milho pode ser substituído integralmente pelo farelo de trigo no concentrado de vacas leiteiras, com produção de leite média de $20 \mathrm{~kg} / \mathrm{dia}$, alimentadas com dietas à base de silagem de milho, sem que ocorra alteração na produção de proteína microbiana e no pH e concentração de amônia ruminal.
\end{abstract}

Palavras-chave: ácido úrico, alantoína, amônia ruminal, derivados de purinas, uréia

\section{Microbial Protein Production and Ruminal Parameters in Dairy Cows Fed Wheat Middlings}

\begin{abstract}
Twelve Holstein cows were allotted to four 4 x 4 Latin square balanced in accordance with the lactation period, with the objective of evaluating the protein production, using the total purine derivatives (PD) excretion, obtained from spot urine collection, the plasma and milk urea and nitrogen(N)-urea, $\mathrm{pH}$ and ruminal ammonia concentration. The four experimental diets were formulated to contain $70 \%$ of corn silage and $30 \%$ of concentrate. Increasing levels of wheat middlings in the concentrate $(0,33,67$ and $100 \%)$ in substitution to the corn meal. The milk urea $(38.8 \mathrm{mg} / \mathrm{dL})$ and $\mathrm{N}$-urea $(18.1 \mathrm{mg} / \mathrm{dL})$ concentrations were not influenced by wheat middlings levels, such as plasma urea $(51.1 \mathrm{mg} / \mathrm{dL})$ e N-urea $(23.8 \mathrm{mg} / \mathrm{dL})$ concentration. The urinary urea, $\mathrm{N}$-urea, allantoin, PD, absorbed purine, $\mathrm{N}$-microbial urinary excretion and milk allantoin concentration were not altered. However, uric acid excretion presented a quadratic response, with maximum value of $40.03 \mathrm{mmol} / \mathrm{day}$ in the wheat middlings level of $36 \%$. The $\mathrm{pH}$ and ruminal ammonia concentration before and after feeding were also not influenced by wheat middlings levels. The corn meal can be substituted integrally by the wheat middlings in the concentrate of dairy cows, with $20 \mathrm{~kg} /$ day average milk production, fed corn silage based diets, with no alteration on microbial protein production and ruminal $\mathrm{pH}$ and ammonia concentration.
\end{abstract}

Key Words: allantoin, purine derivatives, ruminal ammonia, urea, uric acid

\section{Introdução}

As exigências protéicas dos ruminantes são atendidas mediante a absorção intestinal de aminoácidos provenientes principalmente, da proteína microbiana sintetizada no rúmen e da proteína dietética não-degradada no rúmen (Valadares Filho, 1995).
Dessa forma a quantificação da proteína microbiana para os bovinos representa importante área de estudo na nutrição protéica de ruminantes.

Os métodos correntes para a medida da quantidade de compostos nitrogenados microbianos incluem a utilização de marcadores internos tais como ácido ribonucléico (RNA) e ácido

\footnotetext{
${ }^{1}$ Parte da Dissertação de Mestrado apresentada pela primeira autora à UFV.

2 Zootecnista, Mestre em Zootecnia (Nutrição de Ruminantes) pela UFV (carla.a.soares@bol.com.br).

3 Professor do DZO/UFV (jmcampos@ufv.br; scvfilho@ufv.br; aqueiroz@ufv.br; rlana@ufv.br).

4 Professora do DVT/UFV (rilene@ufv.br).

5 Professor do DTRA/UESB (sandrosmendonca@yahoo.com.br).

6 Aluno do Programa de Pós-Graduação em Zootecnia da UFV (rmlv2002@yahoo.com.br).

7 Professor Unimontes.
} 
diaminopimélico (DAPA), ou marcadores externos como nitrogênio $\left({ }^{15} \mathrm{~N}\right)$ e enxofre $\left({ }^{35} \mathrm{~S}\right)$, tornando necessária a utilização de animais fistulados no abomaso ou intestino delgado. Em conseqüência disso, tem havido interesse crescente no desenvolvimento de técnicas não invasivas para estimar a produção de proteína microbiana. A excreção urinária de derivados de purinas (DP) pode constituir um método simples, não invasivo para estimar a produção de proteína microbiana no rúmen. Este método requer coleta total de urina, entretanto tem o potencial de vir a ser simplificado para ser usado em condições de campo (Oliveira et al., 2001). Uma alternativa interessante é o método com base em amostras spot de urina, relacionando a excreção urinária com a concentração de creatinina na urina. É possível a utilização de creatinina como marcador para a estimativa do volume urinário, o que permite estimar a excreção DP e de outros compostos sem a coleta total de urina (Valadares et al., 1997; Oliveira et al., 2001).

A técnica de determinação da excreção urinária de DP admite que os ácidos nucléicos no duodeno são de origem predominantemente microbiana e após digestão intestinal e absorção, tais derivados são proporcionalmente recuperados na urina, principalmente na forma de alantoína, mas também como hipoxantina, xantina e ácido úrico (Perez et al., 1996). Entretanto, na urina de bovinos apenas alantoína e ácido úrico estão presentes, devido a grande atividade da xantina oxidase no sangue e tecidos que converte xantina e hipoxantina a ácido úrico, e este pela ação da uricase é convertido a alantoína (Chen \& Gomes, 1992).

Enquanto a excreção de uréia varia com o teor de proteína bruta da dieta, a excreção urinária de creatinina parece não ser afetada (Valadares et al. 1997), e esta é formada no tecido muscular pela remoção irreversível do fosfato de creatinina, originada do metabolismo de aminoácidos (Harper et al., 1982).

Vários estudos sugerem ser a excreção de creatinina uma função constante do peso vivo e pouco afetada pelo teor de $\mathrm{N}$ da dieta, o que levou muitos autores sugerirem que a avaliação da excreção endógena de $\mathrm{N}$ possa ser derivada de determinações da excreção urinária de creatinina (Ørskov \& Macleod, 1982; Valadares et al., 1997; Rennó et al., 2000).
$\mathrm{O}$ pH, o conteúdo de nitrogênio presente no rúmen e taxa de renovação são fatores químicos e fisiológicos que influenciam o crescimento microbiano, e ambos são influenciados pela dieta e por outros fatores correlacionados, como o nível de consumo, o manejo alimentar, a quantidade e qualidade da forragem, além da proporção volumoso: concentrado da dieta. A diminuição do pH diminui a degradabilidade da proteína, celulose, hemicelulose embora seus efeitos sejam menores sob a digestão do amido. Redução do pH de 6,5 para 5,5 diminuiu a eficiência de síntese microbiana (Hoover \& Stokes, 1991).

Neste experimento, objetivou-se avaliar a produção de proteína microbiana, as concentrações de uréia e $\mathrm{N}$-uréia no plasma e no leite, a excreção urinária de uréia e o pH e a amônia ruminal em vacas leiteiras alimentadas com dietas contendo níveis crescentes de farelo de trigo em substituição ao milho.

\section{Material e Métodos}

O local do experimento, a descrição dos animais, $o$ manejo adotado, as composições bromatológicas dos ingredientes e das dietas experimentais e o delineamento experimental são descritos em Soares et al. (2004).

As coletas de amostras spot de urina (aproximadamente $300 \mathrm{~mL}$ ) e de sangue foram obtidas no $13^{\circ}$ dia de cada período experimental, aproximadamente, quatro horas após a alimentação matinal. Ao término da coleta, a urina foi homogeneizada e alíquotas de $10 \mathrm{~mL}$ foram diluídas imediatamente em $40 \mathrm{~mL}$ de $\mathrm{H}_{2} \mathrm{SO}_{4}(0,036 \mathrm{~N})$. Estas amostras, com $\mathrm{pH}$ ajustado abaixo de 3 para evitar destruição bacteriana dos DP e precipitação do ácido úrico, foram armazenadas a $-20^{\circ} \mathrm{C}$ para posteriores análises de creatinina, uréia, alantoína e ácido úrico.

Nas amostras de sangue, utilizou-se heparina como anticoagulante, sendo posteriormente levadas ao laboratório e centrifugadas a $5.000 \mathrm{rpm}$ durante 15 minutos. O plasma resultante foi armazenado a $-20^{\circ} \mathrm{C}$ para posteriores análises de creatinina e uréia.

As amostras de leite da $1^{\underline{a}}$ e $2^{\underline{a}}$ ordenha, com as quais foi feita uma amostra composta para se procederem as análises de cada animal, foram coletadas no $11^{\mathrm{o}}$ e $14^{\mathrm{o}}$ dia de cada período experimental. Uma alíquota de $10 \mathrm{~mL}$ de leite foi misturada com $5 \mathrm{~mL}$ de ácido tricloroacético a $25 \%$, filtrada em papel-filtro e armazenada a $-20^{\circ} \mathrm{C}$ para posteriores análises de uréia e alantoína. A uréia foi 
determinada na urina, plasma e leite desproteinizado e a creatinina na urina e sangue usando-se kits comerciais (Labtest).

As excreções diárias de N-uréia foram obtidas por meio do produto das concentrações de uréia pelo volume urinário, multiplicando-se por 0,466 ; correspondente aos teores de $\mathrm{N}$ na uréia. A excreção diária média de creatinina $(23,48 \mathrm{mg} / \mathrm{kg} \mathrm{PV})$ foi obtida por Mendonça (2002), utilizando coleta total de urina, e usada para o cálculo do volume urinário a partir da coleta de urina spot.

A excreção total de DP foi à soma das quantidades de alantoína e ácido úrico excretado na urina mais as quantidades de alantoína excretadas no leite, expressas $\mathrm{em} \mathrm{mmol/dia.} \mathrm{As} \mathrm{purinas} \mathrm{absorvidas} \mathrm{(X,} \mathrm{mmol/dia),}$ foram calculadas a partir da excreção de DP (Y, $\mathrm{mmol} /$ dia) por intermédio da equação $\mathrm{Y}=0,85 \mathrm{X}+0,385 \mathrm{PV}^{0,75}$, em que 0,85 é a recuperação de purinas absorvidas como DP e $0,385 \mathrm{PV}^{0,75}$, a contribuição endógena para a excreção de purinas (Verbic et al., 1990).

A síntese de compostos nitrogenados (Y,gN/dia), foi calculada em função das purinas absorvidas (X, $\mathrm{mmol} / \mathrm{dia}$ ), utilizando-se a equação (Chen \& Gomes, 1992): $\mathrm{Y}=70 \mathrm{X} / 0,83 \times 0,134 \times 1000$, onde 70 é o conteúdo de $\mathrm{N}$ de purinas $(\mathrm{mgN} / \mathrm{mmol}), 0,134$ a relação $\mathrm{N}$ purina: $\mathrm{N}$ total nas bactérias (Valadares et al. 1999) e 0,83 a digestibilidade das purinas microbianas.

O líquido ruminal foi coletado utilizando-se sonda esofágica (Ortoloni, 1981). O pH e a concentração de amônia foram determinados nos tempos 0 (antes da alimentação) e 3 horas após a alimentação matinal no $15^{\circ}$ dia. Foram coletados, aproximadamente, $400 \mathrm{~mL}$ de líquido ruminal em recipiente de vidro, que, em seguida, foi filtrado, retirando-se uma alíquota de $40 \mathrm{~mL}$ para cada animal, onde foi determinado imediatamente o $\mathrm{pH}$ por meio de peagâmetro digital. Em seguida adicionou-se $1 \mathrm{~mL}$ de ácido sulfúrico a 50\%, sendo então acondicionadas em vidros devidamente identificados, e armazenadas em congelador a $-5^{\circ} \mathrm{C}$ para posterior determinação da concentração de amônia $\left(\mathrm{N}-\mathrm{NH}_{3}\right)$ ruminal.

Os resultados foram avaliados por meio de análises de variância e de regressão, utilizando o Sistema de Análises Estatísticas e Genéticas (SAEG), UFV (1997), adotando-se nível de significância de 5\%. Como o tratamento é uma variável contínua (nível de substituição), os graus de liberdade deste efeito forma desdobrados em efeitos linear, quadrático e cúbico.

\section{Resultados e Discussão}

Observa-se na Tabela 1, os dados referentes às quantidades de uréia, alantoína e ácido úrico excretados na urina, a quantidade de alantoína excretada no leite e as purinas totais, purinas absorvidas e a produção de $\mathrm{N}$-microbiano, com suas respectivas equações de regressão, coeficientes de determinação $\left(\mathrm{R}^{2}\right)$ e coeficientes de variação $(\mathrm{CV})$.

As excreções urinárias de uréia e $\mathrm{N}$-uréia apresentaram média de 611,8 e $285,09 \mathrm{mg} / \mathrm{kg} \mathrm{PV}$, respectivamente, não havendo diferença entre os tratamentos. Oliveira et al. (2001) encontraram valores de excreções de uréia variando de 217,05 a $358,80 \mathrm{mg} / \mathrm{kg}$ PV, enquanto Silva et al. (2001) relataram média de $395,51 \mathrm{mg} / \mathrm{kg} \mathrm{PV}$, o que mostra que os resultados encontrados no presente estudo ficaram acima daqueles encontrados na literatura. As altas excreções urinárias de uréia e $\mathrm{N}$-uréia encontradas neste experimento, em parte pode ter sido causado por um consumo de proteína pelas vacas além das suas exigências, onde o excesso de proteína é convertido até uréia e excretado na urina.

As excreções urinárias de alantoína não foram afetados pelos tratamentos e apresentaram média de $244,15 \mathrm{mmol} / \mathrm{dia}$. Estes resultados representaram aproximadamente $84,0 \%$ do total excretado de DP, próximo aos encontrados por Oliveira et al. (2001) e Vagnoni et al. (1997) que foram de 85,4 e 86,6\%, respectivamente. A excreção de alantoína na urina reflete a excreção total de DP em aproximadamente $85,0 \%$ (Verbic, 1990), desta forma Puchala \& Kulasek (1992), sugeriram não realizar todas as análises de DP, mas apenas as de alantoína. O que neste caso resultaria em economia de tempo e gasto com análises laboratoriais. A secreção de alantoína no leite, que foi em média $12,24 \mathrm{mmol} / \mathrm{dia}$, também não foi influenciada pelos níveis de farelo de trigo da dieta, provavelmente, devido ao fato de não ter havido variação na produção de leite dos animais utilizados neste experimento.

As excreções urinárias de ácido úrico demonstraram comportamento quadrático $(\mathrm{P}<0,05)$, em função dos níveis de farelo de trigo da dieta, apresentando valor máximo de 39,4 $\mathrm{mmol} /$ dia para o nível de $35,7 \%$ de farelo de trigo. Entretanto, Silva et al. (2001) e Oliveira et al. (2001) não encontraram diferença significativa para as excreções de ácido úrico na urina spot, com valores médios de $23,81 \mathrm{e}$ $29,32 \mathrm{mmol} /$ dia, respectivamente.

R. Bras. Zootec., v.34, n.1, p.345-350, 2005 
Tabela 1 - Excreções urinárias de uréia (EUU), N-ureia, (ENU), alantoína(ALAU) e ácido úrico (ACUU), excreção de alantoína no leite (ALAL), purina totais (PT), purinas absorvidas (PA) e N-microbiano (Nmic) das dietas experimentais e suas respectivas equações de regressão, coeficiente de determinação $\left(R^{2}\right)$ e coeficiente de variação $(\mathrm{CV})$

Table 1 - Urinary excretions of urea (UEU), $N$-urea (NU), alantoin ( $A L$ ) and uric acid (UA), alantoin excretion in the milk (AM), total purines (TP), absorbed purines (AP) and $\mathrm{N}$-microbial (Nmic) of the experimental diets with the respective regression equations, coefficient of determination $\left(R^{2}\right)$ and coefficient of variation $(C V)$

\begin{tabular}{|c|c|c|c|c|c|c|c|}
\hline \multirow{2}{*}{$\begin{array}{l}\text { Itens } \\
\text { Items }\end{array}$} & \multicolumn{4}{|c|}{$\begin{array}{l}\text { Níveis de farelo de trigo } \\
\text { Wheat middlins levels }\end{array}$} & \multirow{2}{*}{$\begin{array}{c}\text { Equação de regressão } \\
\text { Regression equations }\end{array}$} & \multirow[t]{2}{*}{$\mathrm{R}^{2}$} & \multirow[t]{2}{*}{$\mathrm{CV}(\%)$} \\
\hline & 0 & 33 & 67 & 100 & & & \\
\hline$\overline{\mathrm{EUU}}(U E U)(\mathrm{mg} / \mathrm{kgPV})$ & 559,16 & 633,57 & 657,97 & 556,50 & $\mathrm{Y}=611,80$ & & 12,78 \\
\hline $\mathrm{ENU}(N U)(\mathrm{mg} / \mathrm{kgPV})$ & 260,56 & 295,24 & 306,61 & 259,33 & $Y=285,09$ & & 12,78 \\
\hline $\operatorname{ALAU}(A L)(\mathrm{mmol} / \mathrm{dia})$ & 251,17 & 247,31 & 234,85 & 243,27 & $Y=244,15$ & & 16,28 \\
\hline $\operatorname{ACUU}(U A)(\mathrm{mmol} / \mathrm{dia})$ & 35,02 & 39,45 & 36,52 & 25,04 & $*$ & 0,99 & 31,77 \\
\hline $\operatorname{ALAL}(A M)(\mathrm{mmol} / \mathrm{dia})$ & 13,11 & 12,08 & 12,08 & 11,73 & $Y=12,24$ & & 15,24 \\
\hline $\mathrm{PT}(T P)(\mathrm{mmol} / \mathrm{dia})$ & 299,31 & 298,84 & 283,45 & 280,41 & $Y=290,50$ & & 14,00 \\
\hline $\mathrm{PA}(A P)(\mathrm{mmol} / \mathrm{dia})$ & 301,76 & 301,10 & 282,96 & 279,38 & $Y=291,30$ & & 16,43 \\
\hline Nmic (Nmic) (gN/dia) & 219,39 & 218,91 & 205,72 & 203,12 & $Y=211,79$ & & 16,43 \\
\hline
\end{tabular}

* $\mathrm{Y}=34,97+0,25 N T-0,003 N T^{2}$

As excreções totais de DP, purinas absorvidas e $\mathrm{N}$-microbiano não variaram com os níveis de farelo de trigo da dieta, apresentando valores médios de 290,50, 291,30 mmol/dia e 211,80 gN/dia, respectivamente. Silva et al. (2001) também não encontraram diferença significativa para as excreções de DP, purinas absorvidas e $\mathrm{N}$-microbiano na urina spot, que apresentaram média de 311,3, 317,04 mmol/dia e 199,44 gN/dia, respectivamente.

Constam da Tabela 2 a depuração da creatinina, as concentrações de uréia e $\mathrm{N}$-uréia no plasma e as concentrações de uréia e $\mathrm{N}$-uréia no leite em função dos níveis de farelo de trigo da dieta, bem como as respectivas equações de regressão, os coeficientes de determinação $\left(\mathrm{R}^{2}\right)$ e coeficientes de variação.

A depuração da creatinina, uma medida da taxa de filtração glomerular, não foi afetada pelos níveis farelo de trigo da dieta. A média geral encontrada neste experimento de $1,37 \mathrm{~mL} / \mathrm{min} / \mathrm{kg} \mathrm{PV}$ aproximouse dos valores de 2,0 e 1,47 mL/min/kg PV encontrados por Silva et al. (2001) e Valadares et al. (1999).

As concentrações de uréia (UP) e N-uréia (NUP) plasmática expressos em $\mathrm{mg} / \mathrm{dL}$ não variaram entre os tratamentos, também para as concentrações de uréia (UL) e N-uréia (NUL) no leite não apresentaram diferenças significativas. A concentração plasmática de uréia é positivamente relacionada com a ingestão de $\mathrm{N}$, equilibrando-se rapidamente com os compartimentos líquidos do organismo e no leite, e se admite que a concentração de $\mathrm{N}$-uréia no leite reflete a concentração de N-uréia plasmática. A concentra- ção de uréia no leite pode ser um potente indicador do metabolismo protéico em vacas (Roseler et al., 1993; Jonker et al., 1998).

Constam da Tabela 3 os valores médios de $\mathrm{pH}$ e concentração de amônia $\left(\mathrm{N}-\mathrm{NH}_{3}\right)$ ruminal, em mg/ $\mathrm{dL}$, antes e três horas após a alimentação matinal das vacas, assim como suas respectivas médias e coeficientes de variação (CV). As médias gerais de $\mathrm{pH}$ e amônia ruminal antes e três horas após a alimentação não foram influenciados pelos níveis de farelo de trigo da dieta.

A concentração de amônia ruminal nos dois tempos de amostragem do presente estudo ficaram acima do valor de $5 \mathrm{mg} / \mathrm{dL}$ recomendado por Satter \& Slyter (1974), para o máximo crescimento microbiano e ficaram dentro da faixa recomendada por Leng \& Nolan (1984) que sugere uma média de 15 a $20 \mathrm{mg} /$ dL de amônia no líquido de rúmen, como o requerimento de amônia para os microorganismos ruminais.

Os valores médios de $\mathrm{pH}$ antes e após a alimentação, foram 7,17 e 6,69 repectivamente, ou seja, ficaram dentro da faixa recomendada para um máximo crescimento microbiano. Quando o $\mathrm{pH}$ ruminal atinge níveis inferiores a 6,2, ocorre inibição da degradação dos carboidratos estruturais e consequentemente diminui a eficiência de utilização desta energia pelos ruminantes (Lana, 1998).

Dalke et al. (1997) observaram aumento linear do pH ruminal, quando o farelo de trigo substituiu o fubá de milho em $0,5,10$ e $15 \%$, entretanto, quando este substituiu o feno de alfafa em 5 e $10 \%$, não houve variação. 
Tabela 2 - Depuração da creatinina (DC), e concentrações médias de uréia plasmática (UP), N-uréia plasmática (NUP), uréia no leite (UL) N-uréia no leite (NUL) das dietas experimentais com suas respectivas médias e coeficiente de variação $(\mathrm{CV})$

Table 2 - Creatinine clearance (CC), and plasma urea concentrations (PU), plasma N-urea (PNU), urea in the milk (UM), N-urea in the milk (NUM) of the experimental diets with the respectives averages, coefficient of determination $\left(R^{2}\right)$ and coefficient of variation $(\mathrm{CV})$

\begin{tabular}{|c|c|c|c|c|c|c|}
\hline \multirow[t]{2}{*}{$\begin{array}{l}\text { Itens } \\
\text { Items }\end{array}$} & \multicolumn{4}{|c|}{$\begin{array}{l}\text { Níveis de farelo de trigo } \\
\text { Wheat middlings levels }\end{array}$} & \multirow[t]{2}{*}{$\begin{array}{l}\text { Média } \\
\text { Average }\end{array}$} & \multirow[t]{2}{*}{$\mathrm{CV}(\%)$} \\
\hline & 0 & 33 & 67 & 100 & & \\
\hline $\mathrm{CLC}(C C)(\mathrm{mL} / \mathrm{min} / \mathrm{kgPV})$ & 1,34 & 1,37 & 1,36 & 1,40 & $\mathrm{Y}=1,37$ & 9,94 \\
\hline $\mathrm{UP}(P U)(\mathrm{mg} / \mathrm{dL})$ & 50,08 & 53,86 & 52,93 & 47,48 & $Y=51,08$ & 11,99 \\
\hline $\operatorname{NUP}(P N U)(\mathrm{mg} / \mathrm{dL})$ & 23,33 & 25,10 & 24,66 & 22,12 & $Y=23,80$ & 11,99 \\
\hline $\mathrm{UL}(U M)(\mathrm{mg} / \mathrm{dL})$ & 36,83 & 39,87 & 40,02 & 38,42 & $Y=38,78$ & 17,51 \\
\hline NUL $(N U M)(\mathrm{mg} / \mathrm{dL})$ & 17,16 & 18,58 & 18,65 & 17,90 & $Y=18,07$ & 17,51 \\
\hline
\end{tabular}

Tabela 3 - Valores médios de $\mathrm{pH}$, concentração de amônia $\left(\mathrm{NH}_{3}\right)(\mathrm{mg} / \mathrm{dL})$ do líquido ruminal, três horas após a alimentação matinal de vacas recebendo níveis crescentes de farelo de trigo

Table 3 - Average values of $\mathrm{pH}$, ammonia concentration $\left(\mathrm{NH}_{3}\right)(\mathrm{mg} / \mathrm{dL})$ of the ruminal liquid, three hours after the matinal feeding of cows receiving increasing levels from wheat midlings

\begin{tabular}{|c|c|c|c|c|c|c|c|}
\hline \multirow{2}{*}{$\begin{array}{l}\text { Itens } \\
\text { Items }\end{array}$} & \multirow{2}{*}{$\begin{array}{c}\text { Tempo }(\mathrm{h}) \\
\text { Time }(h)\end{array}$} & \multicolumn{4}{|c|}{$\begin{array}{l}\text { Níveis de farelo de trigo (\%) } \\
\text { Wheat middlings levels }(\%)\end{array}$} & \multirow{2}{*}{$\begin{array}{l}\text { Média } \\
\text { Average }\end{array}$} & \multirow[t]{2}{*}{$\mathrm{CV}(\%)$} \\
\hline & & 0 & 33 & 67 & 100 & & \\
\hline $\mathrm{pH}$ & 0 & 7,15 & 7,07 & 7,27 & 7,17 & $Y=7,17$ & 1,74 \\
\hline $\mathrm{pH}$ & 3 & 6,66 & 6,67 & 6,71 & 6,7 & $Y=6,69$ & 3,19 \\
\hline $\mathrm{NH}_{3}$ & 0 & 6,74 & 6,52 & 6,93 & 5,83 & $\mathrm{Y}=6,51$ & 24,34 \\
\hline $\mathrm{NH}_{3}$ & 3 & 13,64 & 15,61 & 14,94 & 15,25 & $Y=14,86$ & 19,07 \\
\hline
\end{tabular}

\section{Conclusões}

O fubá de milho pode ser substituído integralmente pelo farelo de trigo no concentrado de vacas leiteiras, com produção de leite média de $20 \mathrm{~kg} /$ dia, alimentadas com dietas à base de silagem de milho, em uma relação volumoso:concentrado de 70:30, com base na matéria seca, sem que ocorra alteração na produção de proteína microbiana e no $\mathrm{pH}$ e concentração de amônia ruminal.

\section{Literatura Citada}

CHEN, X.B.; GOMES, M.J. Estimation of microbial protein supply to sheep and cattle based on urinary excretion of purine derivatives- an overview of technical details. INTERNATIONAL FEED RESEARCH UNIT. Aberdeen, UK: Rowett Research Institute, 1992. 21p. (Occasional publication)

DALKE, B.S.; SONON, R.N.; YOUNG, M.A et al. Wheat middlings in high-concentrate diets: feedlot performance, carcass characteristics, nutrient digestibilities, passage rates, and ruminal metabolism in finishing steers. Journal of Animal Science, v.75, p.2561-2566, 1997.
HARPER, H.A.; RODWELL, V.W.; MAYES, P.A. Manual de química fisiológica. 5.ed. São Paulo: Atheneu, 1982. 736p.

HOOVER, W.H.; STOKES, S.R. Balancing carbohydrates and proteins for optimium rumen microbial yield. Journal of Dairy Science, v.74, n.10 p.3630-3644, 1991.

JONKER, J.S.; KOHN, R.A.; ERDMAN, R.A. Using milk urea nitrogen to predict nitrogen excretion and utilization efficiency in lactating dairy cows. Journal of Dairy Science, v.81, p.2681-2692, 1998.

LANA, R.P. Microbiologia aplicada a nutrição de ruminantes. In: CONGRESSO NACIONAL DOS ESTUDANTES DE ZOOTECNIA, 1998, Viçosa, MG. Anais... Viçosa, MG: Universidade Federal de Viçosa, 1998. p.139-171.

LENG, R.A.; NOLAN, J.V. Nitrogen metabolism in the rumen. Journal of Dairy Science, v.67, n.5, p.1072-1089, 1984.

MENDONÇA, S.S. Desempenho, síntese de proteína microbiana e comportamento ingestivo de vacas leiteiras alimentadas com cana de açúcar ou silagem de milho. Viçosa, MG: Universidade Federal de Viçosa, 2002. 68p. Dissertação (Mestrado em Zootecnia) - Universidade Federal de Viçosa, 2002.

OLIVEIRA, A.S.; VALADARES, R.F.D.; VALADARES FILHO, S. C. et al. Produção de proteína microbiana e estimativas das excreções de derivados de purinas e de uréia em vacas lactantes alimentadas com rações isoprotéicas contendo diferentes níveis de compostos nitrogenados não-protéicos. Revista Brasileira de Zootecnia, v.30, n.5, p.1621-1629, 2001. 
ØRSKOV, E.R.; MACLEOD, N.A. The determination of the minimal nitrogen excretion in steers and dairy cows and its physiological and practical implications. British Journal of Nutrition, v.47, p.625-636, 1982.

ORTOLONI, E.L. Considerações técnicas sobre o uso da sonda esofágica na colheita do suco de rúmen de bovinos para mensuração do pH. Arquivo Brasileiro de Medicina Veterinária e Zootecnia, v.33, n.2, p.269-275, 1981.

PEREZ, J.F.; BALCELLS, J.; GUADA, J.A. et al. Determination of rumen microbial-nitrogen production in sheep: a comparison of urinary purine excretion with methods using ${ }^{15} \mathrm{~N}$ and purine bases as markers of microbial-nitrogen entering the duodenal. British Journal of Nutrition, v.75, p.699-709, 1996.

PUCHALA, R.; KULASEK, G.W. Estimation of microbial protein flow from the rumen of sheep using microbial nucleic acid and excretion of purine derivatives. Canadian Journal of Animal Science, v.72, p.821-830, 1992.

RENNÓ, L.N.; VALADARES, R.F.D.; LEÃO, M.I. et al. Estimativa da produção de proteína microbiana em novilhos. Revista Brasileira de Zootecnia, v.29, n.4, p.1223-1234, 2000.

ROSELER, D.K.; FERGUSSON, J.D.; SNIFFEN, C.J. Dietary protein degradability effects on plasma and milk urea nitrogen and milk nonprotein nitrogen in holstein cows. Journal of Dairy Science, v.76, p.525-534, 1993.

SATTER, L.D.; SLYTER, L.L. Effect of ammonia concentration on rumen microbial production in vitro. British Journal of Nutrition, v.32, n.2, p.199-208, 1974.

SILVA, R.M.N.; VALADARES, R.F.D.; VALADARES FILHO, S.C. et al. Uréia para vacas em lactação. 2. Estimativas do volume urinário, da produção microbiana e da excreção de uréia. Revista Brasileira de Zootecnia, v.30, n.6, p.1948-1957, 2001.

SOARES, C.A.; CAMPOS, J.M.S.; VALADARES FILHO, S.C. et al. Consumo, digestibilidade aparente, produção e composição do leite de vacas leiteiras alimentadas com farelo de trigo. Revista Brasileira de Zootecnia, v.33, n.6, p.2161-2169, 2004 (Supl. 2).
UNIVERSIDADE FEDERAL DE VIÇOSA - UFV. SAEG (Sistema de Análises Estatísticas e Genéticas). Versão 7.1. Viçosa, MG, 1997. 150p. (Manual do usuário)

VAGNONI, D.B.; BRODERICK, M.K.; CLAYTON, R.D. et al. Excretion of purine derivatives by Holstein cows abomasally infused with incremental amounts of purines. Journal of Dairy Science, v,80, p.1695-1702, 1997.

VALADARES FILHO, S.C. Eficiência de síntese de proteína microbiana, degradação ruminal e digestibilidade intestinal da proteína bruta, em bovinos. In: SIMPÓSIO INTERNACIONAL SOBRE EXIGÊNCIAS NUTRICIONAIS DE RUMINANTES, 1995, Viçosa, MG. Anais... Viçosa, MG: Universidade Federal de Viçosa, 1995. p.1259-1263.

VALADARES, R.F.D.; BRODERICK, G.A.; VALADARES FILHO, S.C. et al. Effect of replacing alfafa silage with high moisture corn on ruminal protein syntesis estimated from excretion of total purine derivates. Journal of Dairy Science, v.82, n.12, p.2686-2696, 1999.

VALADARES, R.F.D.; GONÇALVES, L.C.; SAMPAIO, I.B. et al. Níveis de proteína em dietas de bovino. 4. Concentrações de amônia ruminal e uréia plasmática e excreções de uréia e creatinina. Revista Brasileira de Zootecnia, v.26, n.6, p.270-1278, 1997.

VERBIC, J.; CHEN, X.B.; MACLEOD, N.A. et al. Excretion of purine derivatives by ruminants. Effect of microbial nucleic acid infusion on purine derivative excretion by steers. Journal Agricultural Science, v.114, n.3, p.243-246, 1990. 